NASA Technical Memorandum 106846

AIAA-95-0031

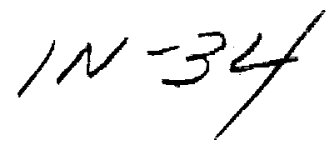

\title{
Flow Coefficient Behavior for Boundary Layer Bleed Holes and Slots
}

B.P. Willis, D.O. Davis, and W.R. Hingst

Lewis Research Center

Cleveland, Ohio

Prepared for the

33rd Aerospace Sciences Meeting and Exhibit

sponsored by the American Institute of Aeronautics and Astronautics

Reno, Nevada, January 9-12, 1995

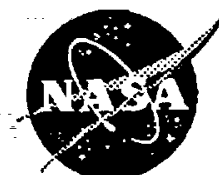

National Aeronautics and Space Administration

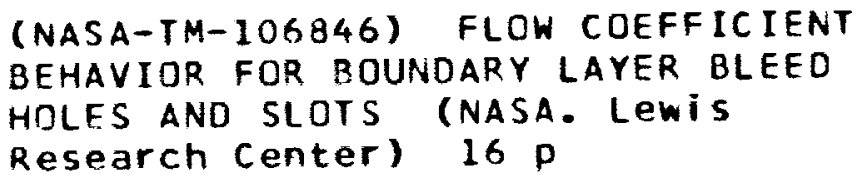




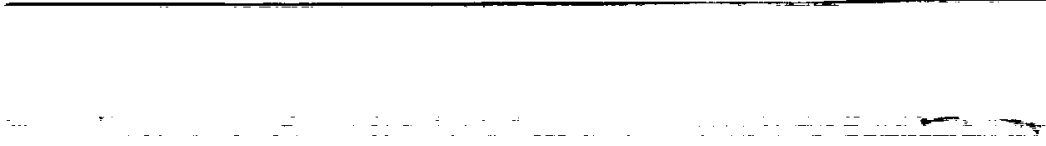




\title{
FLOW COEFFICIENT BEHAVIOR FOR BOUNDARY LAYER BLEED HOLES AND SLOTS
}

\author{
B. P. Willis", D. O. Davis", and W. R. Hingst" \\ NASA Lewis Research Center, Cleveland, Ohio
}

Abstract
investigation into the flow coef-
aine boundary layer bleed orifice ficient behavior for nine boundary layer bleed orifice configurations is reported. This test was conducted for the purposes of exploring boundary layer control through mass flow removal and does not address issues of stability bleed. Parametric data consist of bleed region flow coefficient as a function of Mach number, bleed plenum pressure, and bleed orifice geometry. Seven multiple bole configurations and two single slot configurations were tested over a supersonic Mach number range of 1.3 to 2.5 [nominal]. Advantages gained by using multiple holes in a bleed region instead of a single spanwise slot are discussed and the issue of modelling an entire array of bleed orifices based on the performance of a single orifice is addressed. Preconditioning the flow approaching a $90^{\circ}$ inclined (normal) hole configuration, resulted in a significant improvement in the performance of the configuration. The same preconditioning caused only subtle changes in performance for a $20^{\circ}$ inclined (slanted) configuration.

\section{Nomenclature}

\begin{tabular}{|c|c|c|}
\hline$\sum A$ & $=$ & total bleed area \\
\hline$C_{d}$ & $=$ & ASME nozzle discharge coefficient \\
\hline$d$ & $=$ & $\begin{array}{l}\text { orifice diameter (width), ASME nozzle } \\
\text { throat diameter }\end{array}$ \\
\hline$D$ & $=$ & $\begin{array}{l}\text { diameter of approach pipe upstream of } \\
\text { ASME nozzle }\end{array}$ \\
\hline$E_{f}$ & $=$ & ASME nozzle thermal expansion factor \\
\hline$H_{\text {ine }}$ & $=$ & incompressible shape factor \\
\hline$L$ & $=$ & orifice length (depth) \\
\hline$\dot{m}$ & $=$ & mass-flow rate \\
\hline$M$ & $=$ & Mach number \\
\hline$P$ & $=$ & static pressure \\
\hline$P_{t}$ & $=$ & total pressure \\
\hline$\Delta P$ & $=$ & $\begin{array}{l}\text { ASME nozzle differential pressure, } \\
P_{1}-P_{2}\end{array}$ \\
\hline$Q$ & $=$ & sonic flow coefficient \\
\hline$R e$ & $=$ & Reynolds number \\
\hline
\end{tabular}

'Research Engineer, Inlet, Duct, and Nozzle Flow Physics Branch; Member AIAA

$$
\begin{array}{ll}
T_{t} & =\text { total temperature } \\
\overline{x, y, z} & =\text { cartesian coordinate system } \\
Y & =\text { ASME nozzle expansion ratio } \\
\delta & =\text { boundary-layer thickness } \\
\delta^{*} & =\text { displacement thickness } \\
\theta & =\text { momentum thickness }
\end{array}
$$

\begin{tabular}{|c|c|c|}
\hline & & Subscripts \\
\hline 0 & $=$ & condition in wind-tunnel plenum \\
\hline & $=$ & condition at upstream reference plane \\
\hline plenum & $=$ & condition in the bleed plenum \\
\hline 1 & & pipe section upstream of the flow nozzle \\
\hline 2 & & $\begin{array}{l}\text { pipe section downstream of the flow } \\
\text { nozzle }\end{array}$ \\
\hline
\end{tabular}

Objective

As part of an effort to provide technology tools to allow for more efficient design of bleed systems in supersonic inlets, an experimental investigation was initiated to explore the fundamental dynamics of bleed mass flow removal as it applies to boundary layer control. The objective of this effort can be divided into two parts: 1) provide data that can be used to develop and test global modeling schemes for bleed regions, and 2) provide parametric data describing bleed orifice efficiencies for a range of supersonic conditions. Part one focuses on contributing to a long tern goal of effectively predicitng the behavior of bleed regions in inlet systems via computational fluid dynamics. Global modeling schemes for bleed regions are a necessity since including each individual bleed orifice in the computational domain can be cost prohibitive. Part two focuses on developing a parametric database for near term use by inlet aerodynamic designers. As presented here, the data serves part two of the objective.

Introduction

Background

Renewed interest in a high speed civil transport has brought along its associated concerns surrounding the performance of mixed compression supersonic inlets. Mixed compression supersonic inlets present two key challenges to an inlet aerodynamicist. First, the shock wave/boundary layer interactions inherent in this type of inlet cause a reduction in performance of the system via boundary layer separation. Distortions introduced by such separations, along with 'displacing' the shock wave 
pattern, reduce the efficiency of the inlet. In the limit this reduction becomes unacceptable. Second, the shock wave system at its normal shock wave terminus is neutrally stable thus making it susceptible to a phenomenon know as 'unstart'. During an unstart the inlet operation transitions from maximum thrust to maximum drag in milliseconds. Unstarts in the mixed compression inlets of the SR71 aircraft have resulted in the pilot's helmet cracking as his head impacts the cockpit canopy due to the sudden deceleration caused by the event. This phenomenon is unacceptable for obvious reasons. During the past two decades of research on mixed compression supersonic inlets, aerodynamicists have consistently turned to the technique of mass flow removal, colloquially referred to as 'bleed', when addressing these two challenges. The difference between boundary layer control bleed and stability bleed begins with the amount of mass flow that needs to be removed (boundary layer control: percentage of boundary layer mass flow removed versus stability: percentage of inlet mass capture flow removed) and continues to diverge in application. The effort discussed in this paper focuses on boundary layer control bleed as it applies to shock wave/boundary layer interactions. Issues regarding stability bleed are not addressed.

Boundary layer control bleed, when applied in the region of a reflected oblique shock wave/boundary layer interaction, controls boundary layer separation by increasing the average kinetic energy of the boundary layer thus belping it overcome the adverse pressure gradient associated with the shock wave. The porous surface, or bleed region, may be a series of discrete orifices or a single large slot A large percentage of the data concerning the effectiveness of this technique was gathered from systems tests of mixed compression supersonic inlets ${ }^{1-6}$ ergo the effectiveness is defined from a systems point of view. The work of McLafferty and Ranard ${ }^{7}$ has stood for years as the sole investigation into the fundamental behavior of the mass flow through a porous surface consisting of discrete holes and most, if not all, of the bleed systems used in the previously mentioned systems tests were designed based on the data from this work. However, these bleed systems needed multiple rows of holes in order to remove enough mass to be effective whereas McLafferty used only two rows for the bulk of his work. The work discussed herein begins to extend McLafferty's efforts into the arena of realistic bleed systems by establishing baseline performance data for several configurations of multiple rows of holes (or single spanwise slots).

\section{Boundary Layer Control Bleed}

Boundary layer control bleed uses a suction pressure differential across a porous surface, or bleed region, to draw off the low momentum fluid associated with the boundary layer. The basic objective is to 'improve' the boundary layer, i.e. increase its average kinetic energy, making it less susceptible to separation caused by

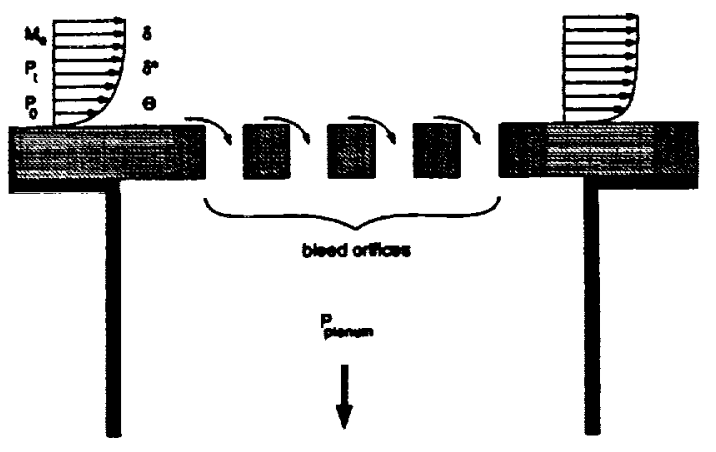

Fig. 1 Bleed experiment schematic.

the presence of an adverse pressure gradient. A typical bleed experiment, see Fig. 1, has a number of features that can be divided into aerodynamic and geometric subsets. Aerodynamic features are the free stream conditions, approach boundary layer characteristics, and the suction pressure differential. Geometric features are orifice size, orifice shape, orifice spacing or porosity, and bleed plenum size. Scaling of the orifice size to the approaching boundary layer characteristic offers yet another parametric dimension. Table 1 provides a compilation of the variables associated with these three subsets. The geometric variables are schematically defined in the section on Bleed Configuration Hardware. An experimen-

\begin{tabular}{|c|c|}
\hline \multicolumn{2}{|r|}{ Aerodynamic Variables } \\
\hline $\mathbf{P}_{\mathrm{L}, 0}$ & freestream total pressure \\
\hline$P_{0}$ & freestream static pressure \\
\hline $\mathbf{M}$ & Mach number \\
\hline $\mathbf{P}_{\text {plenum }}-\mathbf{P}_{\mathbf{0}}$ & suction pressure differential \\
\hline$\delta * 1 \theta$ & health of the boundary layer \\
\hline \multicolumn{2}{|r|}{ Geometric Variables } \\
\hline d & orifice diameter \\
\hline Ld & orifice aspect ratio \\
\hline P. $\mathbf{Y} \mathbf{d}$ & transverse spancing \\
\hline$Y_{A}^{\prime} \mathrm{A}$ & intercolum spacing \\
\hline $\mathrm{x} d \mathrm{~A}$ & streamwise spacmg \\
\hline$\alpha$ & inclination angle of orifice axis \\
\hline$\beta$ & NACA flush inlet inclination angle \\
\hline $\mathbf{N}$ & number of rows of orifices \\
\hline r/d & edge radius ratio \\
\hline $\mathbf{A} / \mathbf{A}^{\prime}$ & entrance area to exit area ratio \\
\hline orifice shape & round, square, louvre, ...... \\
\hline \multicolumn{2}{|r|}{ Scaling Factors } \\
\hline$\delta / d$ & scaling to boundary layer thickness \\
\hline$\delta * / \mathrm{d}$ & scaling to the displacement thickness \\
\hline$\theta / \mathrm{d}$ & scaling to the momentum thickness \\
\hline
\end{tabular}

Table 1 Available variables for a typical bleed experiment. 
tal matrix designed to cover all the variables described in Table 1 is not feasible. The present investigation covers a very small portion of these parameters.

Evaluation of a bleed configuration is determined by how efficiently it removes the low momentum fluid associated with the boundary layer. This efficiency at removing mass from the boundary-layer is typically quantified by the sonic flow coefficient defined as follows:

$$
Q=\frac{\dot{m}}{\dot{m}_{\text {ideal, ehoked }}}
$$

where $\dot{m}_{\text {ideel, choked }}$ is the choked flow through the total bleed area for a discharge coefficient of 1.0. The following equation is used to compute this reference value:

$$
\dot{m}_{i d e a l, \text { choked }}=\frac{0.5318 P_{t} \sum A}{\sqrt{T_{t}}}
$$

Defining the efficiency of the bleed configuration in this manner allows an inlet designer to determine the amount of open area required to remove a given amount of mass (usually 'given' as a percentage of the boundary layer mass flow rate). Such activity has an associated systems cost which is embodied in a bleed drag coefficient and is directly related to the bleed plenum pressure. Showing the sonic flow coefficient, $Q$, as a function of the bleed plenum static pressure, $P_{\text {plenum }}$, normalized by the freestream total pressure, $P_{t}$, provides a bleed mass flow recovery curve analogous to a supersonic inlet mass flow recovery curve (with which inlet designers are familiar). Figure 2 represents a generic set of recovery curves. In keeping with this analogy the various regions of the bleed mass flow recovery curves will be referred to as subcritical, critical or choked, and supercritical throughout the discussion of results. Plotting the data in this fashion provides a quick look at the pressure recovery, i.e. pressure loss, that will be incurred from operating the bleed configuration at a particular sonic flow coefficient.

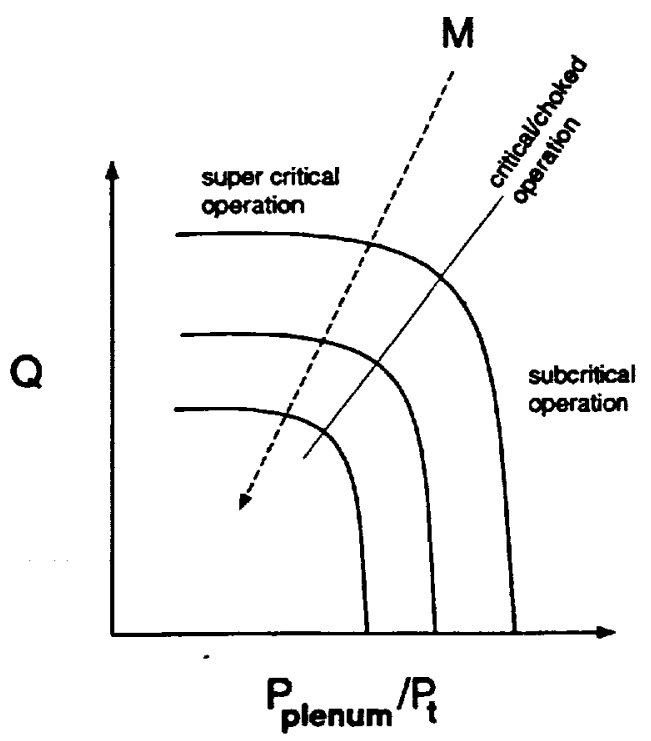

Fig. 2 Generic set of bleed mass flow recovery curves

\section{Experimental Program}

Wind Tunnel Installation

The experiments were performed in the NASA Lewis Research Center 1X1 ft. Supersonic Wind Tunnel (SWT) which is a continuous-flow facility with Mach number variation provided by replaceable nozzle blocks. A schematic of the $1 X 1$ SWT experiment is shown in Fig. 3a. The approach boundary-layer is the naturally occurring boundary-layer on the wind tunnel wall. The bleed region is contained in an interchangeable sidewall insert which is flush mounted with the test section sidewall surface. Figure $3 b$ provides a plan view of the installation. Boundary layer fences were used to isolate the wind tunnel test section corner flow thereby establishing a quasi-two dimensional flow field over the bleed region.

Bleed mass flow exhausts into a large plenum where plenum static pressure, $P_{\text {plenum }}$, was measured. ASME unchoked nozzles were used to measure the bleed mass flow rate which was controlled by a choked mass flow plug arrangement. Controlling the mass flow rate is analogous to controlling the bleed plenum pressure. A suction pressure differential across the bleed region was supplied by a 450 psi air ejector dumping into the lab-wide altitude exhaust system. Maintaining a pressure ratio across the mass flow plug of approximately 0.4 or less provided a

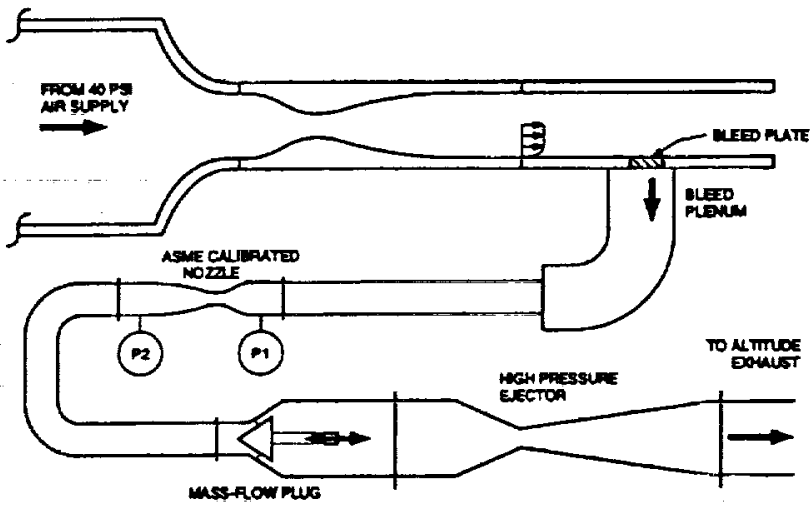

a) General arrangement.

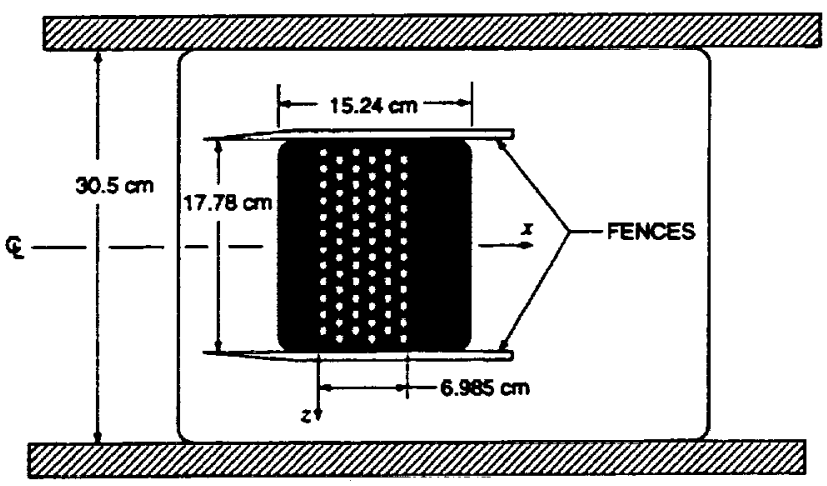

b) Plan view of slot installation.

Fig. 3 Flow coeficient behavior experiment wind-tunnel installation. 
Table $21 \mathrm{ft}$. by $1 \mathrm{ft}$. supersonic wind-tunnel operating conditions.

\begin{tabular}{||c||c|c|c|c||}
\hline & \multicolumn{4}{|c||}{$M_{\text {ref }}$} \\
\cline { 2 - 6 } & 1.27 & 1.58 & 1.98 & 2.46 \\
\hline$P_{i, 0} \mathrm{kPa}$ & 89.6 & 103.4 & 137.9 & 172.4 \\
\hline$P_{0} \mathrm{kPa}$ & 33.7 & 25.0 & 18.2 & 10.7 \\
\hline$T_{t, 0}{ }^{\circ} \mathrm{K}$ & 293.0 & 293.0 & 293.0 & 293.0 \\
\hline $\begin{array}{c}R e \times 10^{-7} \\
/ \mathrm{m}\end{array}$ & 1.35 & 1.34 & 1.77 & 1.75 \\
\hline$\delta_{\text {ref }} \mathrm{cm}$ & 2.24 & 2.10 & 2.44 & 2.63 \\
\hline$\delta_{\text {ref }}^{*} \mathrm{~cm}$ & 0.393 & 0.436 & 0.567 & 0.717 \\
\hline$\theta_{\text {ref }} \mathrm{cm}$ & 0.209 & 0.192 & 0.202 & 0.198 \\
\hline$H_{\text {ine }}$ & 1.259 & 1.275 & 1.262 & 1.26 \\
\hline$C_{f, \text { ref }} \times 10^{3}$ & 2.07 & 1.69 & 1.50 & 1.29 \\
\hline \hline
\end{tabular}

fine control over the bleed plenum pressure via a choked area effect at the mass flow plug location. This choking action also isolated the bleed plenum/mass flow measurement system from any fluctuations in the lab-wide altitude exhaust system. These fluctuations could be as much as $0.689 \mathrm{kPa}$ in magnitude enough to overwhelm the differential pressure reading of the ASME nozzles at low bleed flow rates. With tunnel conditions being held constant, a typical bleed configuration evaluation consisted of a mass flow plug sweep containing approximately 20 stops. The resulting bleed mass flow recovery curves, from zero mass flow to choked flow, for nine different bleed configurations are the subject of this paper.

Data were obtained for four wind-tunnel operating conditions. These conditions are referred to by the wind-tunnel core Mach number measured in the upstream reference plane. Table 2 summarizes the wind-tunnel plenum condition and the boundary-layer characteristics measured in the reference plane for each of the reference Mach numbers. The unit Reynolds number reported in this table is based on the plenum conditions and the reference plane core Mach number $\left(M_{r \ell} f\right)$.

Instrumentation and Uncertainty

The critical instrumentation and its associated uncertainty are the pressure transducers used in conjunction with the ASME unchoked nozzles to measure the bleed mass flow rate. Figure 4 provides a schematic of this measurement system and its instrumentation. Two delta

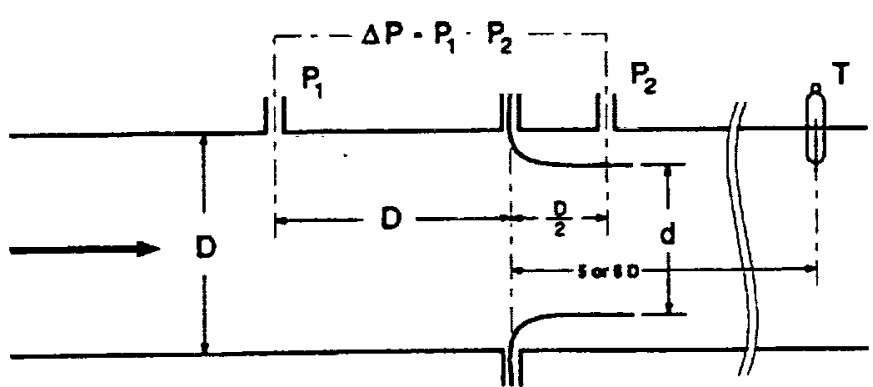

Fig. 4 Diagram of the ASME unchoked nozzle flow measurement system showing location of pipe pressure taps.

pressure transducers and one absolute pressure transducer were used to record the pressure differential across the nozzle, $\left(P_{1}-P_{2}\right)$, and the total pressure upstream of the nozzle, $P_{1}$, respectively. Low tunnel static pressures, $P_{0}$, that exist at the test conditions result in a bleed plenum pressure range $P_{0} \geq P_{1} \geq 0.3 P_{0}$. Four thermocouples were used to provide an average temperature of the flow downstream of the ASME nozzle. Implementation of this instrumentation follows the guidelines established by the ASME $^{8}$. The accuracy and resolution of the transducers follows as:

$$
\begin{array}{ccc} 
& \mathbf{P}_{1} & \Delta \mathbf{P} \\
\text { accurracy } & \pm 15 \% \text { of rdg. } & \pm 15 \% \text { of rdg. } \\
\text { resolution } & \pm 5 \times 10^{-3} \text { tor } & \pm 1.75 \times 10^{-1} \text { tor }
\end{array}
$$

For the equation used to calculate the bleed mass flow rate,

$$
\dot{m}=0.86253 \frac{C_{d} E_{f} Y d^{2}}{\sqrt{1-\left(\frac{d}{D}\right)^{4}}} \sqrt{\frac{p_{1} \Delta p}{T_{1}}} \quad l b_{m} / \mathrm{sec}
$$

a "practical working formula" for calculating its uncertainty, $\frac{\delta \dot{m}}{\dot{m}}$, is given in ASME MFC-3M-1985. The formula states that only the following uncertainties are to be included: $C_{d}, Y, D, d^{2}, \Delta p$, and $p_{1}$. Using the values given by the ASME standard $d^{9}$ for $C_{d}, Y, D$, and $d^{2}$ in conjunction with the pressure ranges experienced in the system yields the results shown in Table 3 . Table 3 provides ranges for the values of $p_{1}$ and $\Delta p$ which bracket the operating conditions of the system: near zero flow to maximum flow".

Carrying the uncertainty analysis through to the sonic flow coefficient (see eq. 2) and its subsequent display as a function of the ratio of the bleed plenum

- It is interesting to note that the given ASME standard 9 uncertainty value for $C_{d}, \delta C_{d} / C_{d}=0.02$, is the dominant function determining the uncertainty of the mass flow measurement for this system. 


\begin{tabular}{|c|c|c|c|c|}
\hline & \multicolumn{4}{|c|}{ Mach Number } \\
\hline & 1.27 & 1.58 & 1.98 & 2.46 \\
\hline $\begin{array}{l}\text { P1 range } \\
\text { (psia) }\end{array}$ & $5.0 \cdot 1.7$ & $4.0-1.2$ & $2.6-0.8$ & $1.6-0.4$ \\
\hline $\begin{array}{c}\Delta p \\
\text { mange } \\
\text { (psia) }\end{array}$ & $\begin{array}{c}0.005 \\
0.4\end{array}$ & $0.005-0.3$ & $0.005 \cdot 0.1$ & $0.005-0.1$ \\
\hline$\delta \mathbf{p} / \mathbf{p}$ & .0015 & .0015 & .0015 & .0015 \\
\hline$\delta \Delta p / \Delta p$ & .0015 & .0015 & .0015 & .0015 \\
\hline$\frac{\delta \dot{m}}{\operatorname{m}}$ & $\begin{array}{l}.0220 \\
.0218\end{array}$ & $\begin{array}{l}.0220 \\
.0218\end{array}$ & $.0220-.0218$ & $.0220-.0218$ \\
\hline
\end{tabular}

Table 3 Uncertainty values of the bleed mass flow rate over the range of operating conditions experienced throughout the test.

pressure, $P_{\text {plenum, }}$, to the tunnel total pressure, $P_{\text {ref }}$, results in the following uncertainty values:

$$
\begin{gathered}
\frac{\delta \dot{m}_{\text {ideal }, \text { choked }}}{\dot{m}_{\text {ideal,choked }}}=[0.0091] \text { maximum } @ M=1.27 \\
\frac{\delta Q}{Q}=[0.0241] \text { maximum } \\
\frac{\delta \frac{P_{\text {slenim }}}{P_{t}}}{\frac{P_{\text {plenym }}}{P_{t}}}=[0.0061,0.0065,0.0093,0.0176]
\end{gathered}
$$$$
\text { for } M a c h=1.27,1.58,1.98,2.46
$$

where the accuracy of $P_{\text {pienum }}$ and $P_{t}$ are 0.007 psi and 0.045 psi respectively.

\section{Bleed Configuration Hardware}

Nine bleed configurations, labeled $\mathrm{Cl}$ through $\mathrm{C}$, were tested at the conditions listed in Table 2. The configurations tested were designed to meet various goals and by no means are they representative of a definitive set. Configurations $\mathrm{Cl}$ through $\mathrm{C5}$ are considered standard configurations because the associated orifice shapes are commonly used for bleed regions in inlet systems. Table 4 provides a list of the geometric characteristics of these standard configurations.

Configurations $\mathrm{C} 6$ through $\mathrm{C} 9$ are considered nonstandard because of the application of flow field preconditioning upstream of the orifice entrance. This preconditioning is acbieved by merging a NACA flush inlet ${ }^{10}$ geometry with a standard hole geometry. Flow is directed into the bleed orifice by the vortical activity associated with the fluid dynamics of the flush inlet. Since the flow is supersonic, the flush inlet provides a small amount of flow turning via an expansion wave thus directing flow into the orifice. The local speeding up of the flow creates a pressure gradient across the streamwise edge of the flush inlet which also induces flow into the orifice. Configuration $C 9$ is a NACA flush inlet backed by a diffusing channel, in essence turning the entire orifice into a small inlet system. Table 5 provides a list of the geometric characteristics of these nonstandard configurations. Recalling the tunnel reference conditions, the aerodynamic scaling of orifice diameter, $\mathrm{d}$, to the boundary layer characteristic $\delta^{*}$ is on the order of one. Porosity for the multiple row configurations is considered constant except for $C 9$.

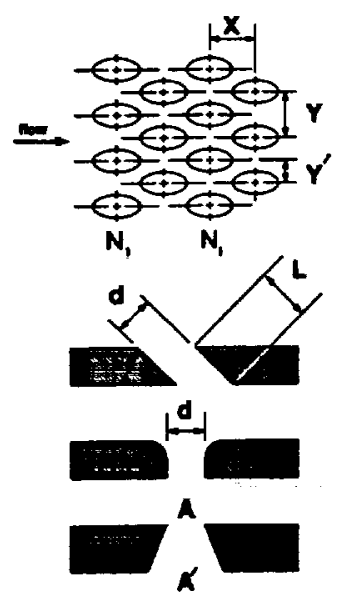

\begin{tabular}{|c|c|c|c|c|c|}
\cline { 2 - 7 } \multicolumn{1}{c|}{} & $\mathrm{Cl}$ & $\mathrm{C} 2$ & $\mathrm{C} 3$ & $\mathrm{C} 4$ & $\mathrm{C5}$ \\
\hline $\mathrm{d}$ & 0.635 & 0.635 & 0.635 & 1.00 & 1.00 \\
\hline $\mathrm{L} / \mathrm{d}$ & 1.0 & 1.0 & 2.92 & 2.54 & 7.42 \\
\hline $\mathrm{Y} / \mathrm{d}$ & 2.0 & 2.0 & 2.0 & - & - \\
\hline $\mathrm{Y}^{\prime} / \mathrm{d}$ & 1.0 & 1.0 & 1.0 & - & - \\
\hline $\mathrm{X} / \mathrm{d}$ & 2.0 & 2.0 & 2.78 & - & - \\
\hline$\alpha$ & $90^{\circ}$ & $90^{\circ}$ & $20^{\circ}$ & $90^{\circ}$ & $20^{\circ}$ \\
\hline $\mathrm{N}$ & 6 & 6 & 6 & 1 & 1 \\
\hline $\mathrm{A} / \mathrm{A}^{\prime}$ & 1.0 & 1.4 & 1.0 & 1.0 & 1.0 \\
\hline$\tau / \mathrm{d}$ & 0.0 & 0.0 & 0.0 & 100 & 0.0 \\
\hline$\Sigma \mathrm{A}$ & 23.75 & 23.75 & 23.75 & 16.30 & 16.30 \\
\hline
\end{tabular}

Table 4 Geometric characteristics of standard bleed orifice configurations: C1 through C5. 

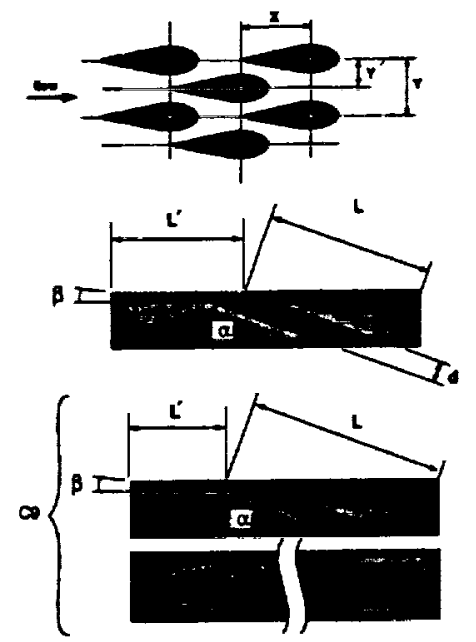

\begin{tabular}{|c||c|c|c|c|}
\cline { 2 - 5 } & C6 & $C 7$ & $C 8$ & $C 9$ \\
\hline $\mathrm{d}$ & 0.635 & 0.635 & 0.635 & 1.01 \\
\hline $\mathrm{N}^{\prime} \mathrm{d}$ & 2.0 & 3.11 & 5.84 & 5.0 \\
\hline $\mathrm{L}^{\prime} / \mathrm{d}$ & 2.6 & 2.6 & 2.6 & 2.5 \\
\hline $\mathrm{Y} / \mathrm{d}$ & 2.0 & 2.0 & 2.0 & 2.0 \\
\hline $\mathrm{Y}^{\prime} / \mathrm{d}$ & 1.0 & 1.0 & 1.0 & 1.0 \\
\hline $\mathrm{X} / \mathrm{d}$ & 2.0 & 2.0 & 2.78 & 4.0 \\
\hline$\alpha$ & $90^{\circ}$ & $40^{\circ}$ & $20^{\circ}$ & $21^{\circ}$ \\
\hline$\beta$ & $7^{\circ}$ & $7^{\circ}$ & $7^{\circ}$ & $7^{\circ}$ \\
\hline $\mathrm{N}$ & 6 & 6 & 5 & 3 \\
\hline $\mathrm{A} / \mathrm{A}^{\prime}$ & 1.0 & 1.0 & 1.0 & 2.0 \\
\hline $\mathrm{r} / \mathrm{d}$ & 0.0 & 0.0 & 0.0 & 0.0 \\
\hline$\Sigma \mathrm{A}$ & 23.75 & 23.75 & 19.79 & 7.42 \\
\hline
\end{tabular}

Table 5 Geometric characteristics of nonstandard bleed orifice configurations: C6 through C9.

Results and Discussion

\section{Sonic Flow Coefficient}

Sonic flow coefficient distributions were measured for the case of an undistorted approach boundary-layer for each of the reference Mach numbers in Table 2 for the nine bleed configurations previously described. These distributions are shown in Figures 5 through 13. Two different scales are used for these plots because of the dramatic difference between the performance of $90^{\circ}$ inclined (normal) configurations and the $20^{\circ}$ inclined configurations. Figures 14 through 26 display some unique comparisons of these nine configurations.

Configuration $\mathrm{C} 4$ was the first configuration tested and two ASME nozzles were used to test the nozzle sizing technique applied to provided the best measurement range each configuration. Nozzle sizing for each configuration was based on the data of McLafferty and Ranard ${ }^{7}$ keeping in mind that the nozzle Mach number should not exceed 0.7 . The open and closed symbols in figure 8 represent data measured with these two different diameter ASME nozzles. The solid symbols represent a nozzle with a diameter of $6.096 \mathrm{~cm}$ and the open symbols represent a nozzle with a diameter of $8.225 \mathrm{~cm}$. The switch to the larger nozzle was made at the lower Mach numbers because the relatively large bleed mass flow associated with these conditions caused the Mach number of the smaller nozzle to exceed 0.8 . This data highlights the compressibility effects on the ASME nozzle mass flow measurement system. A corrected flow rate technique was used to check the nozzle Mach number for each configuration at its maximum flow rate to insure that an appropriate nozzle size was being used.

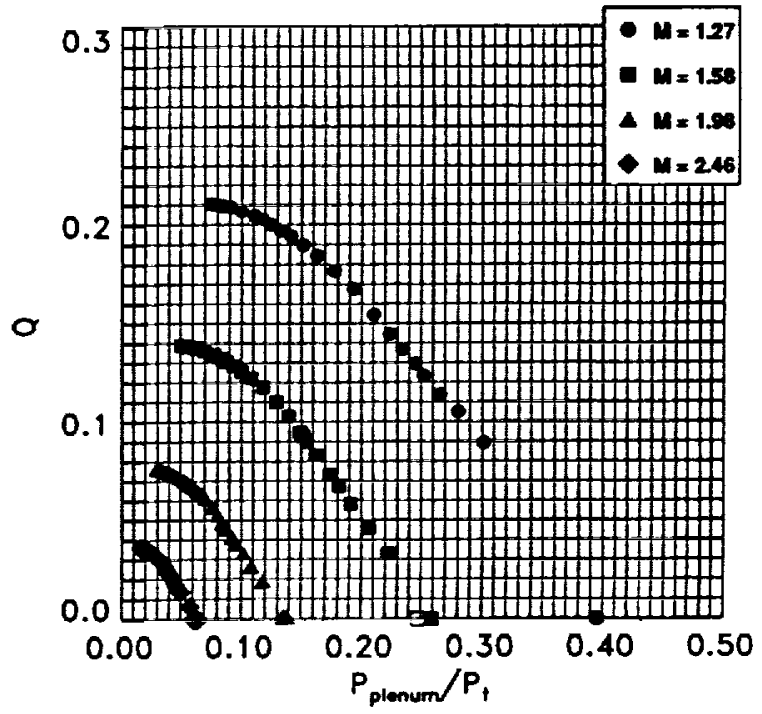

Fig. 5 Sonic flow coefficient distributions: C1

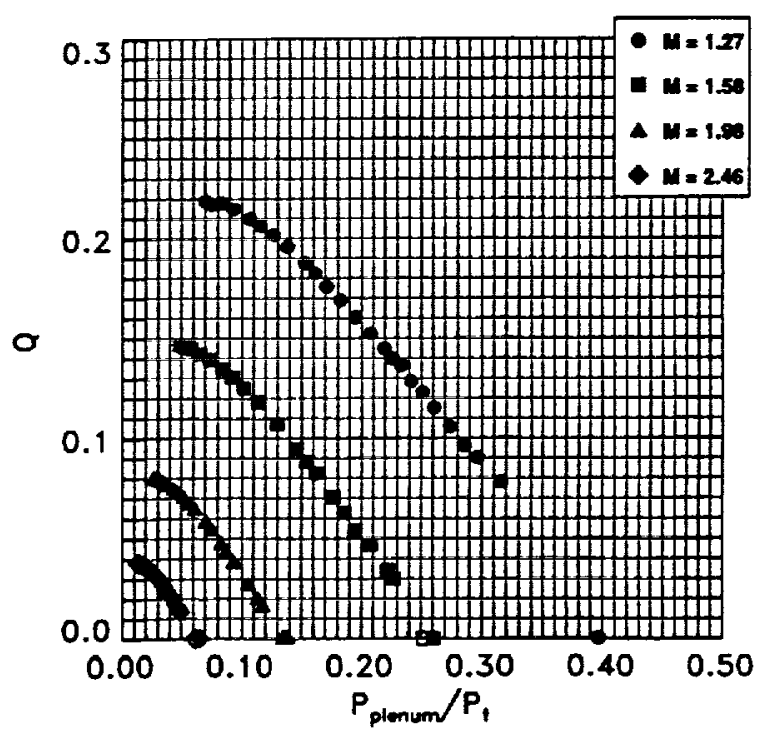

Fig. 6 Sonic flow coefficient distributions: C2 


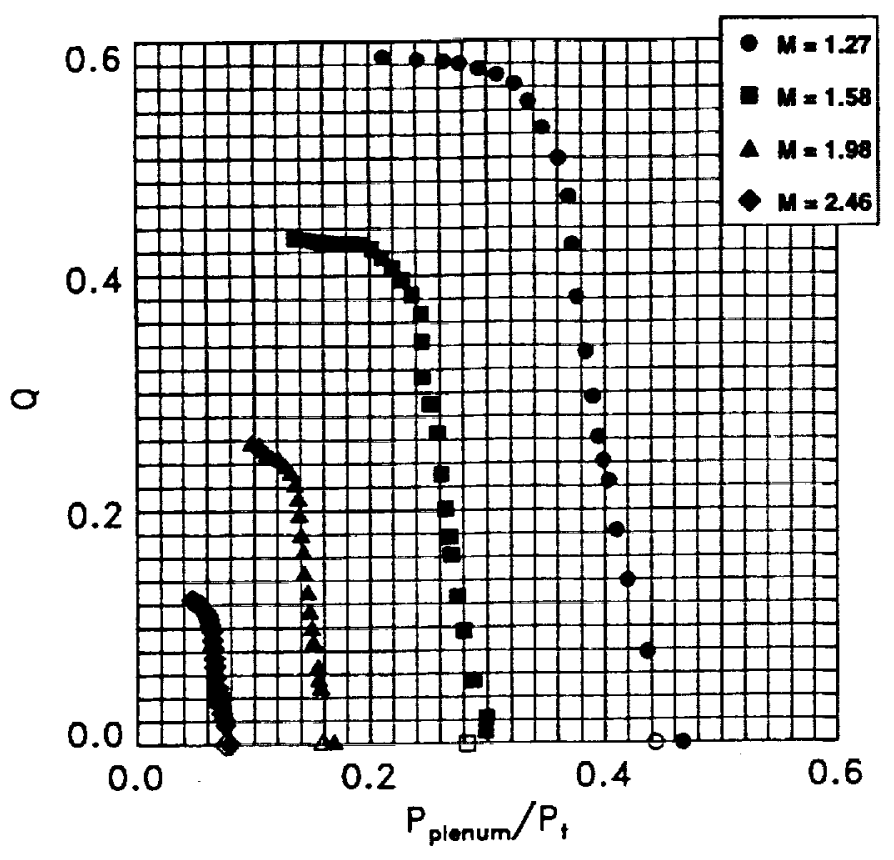

Fig. 7 Sonic flow coefficient distributions: C3

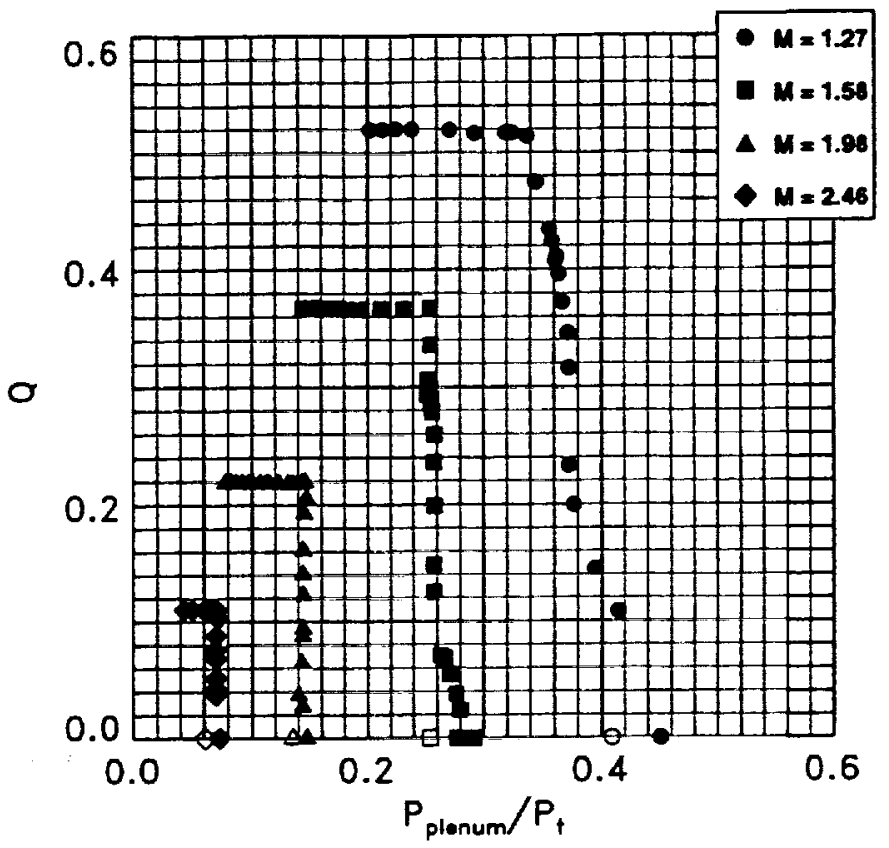

Fig. 9 Sonic fiow coefficient distributions: C5

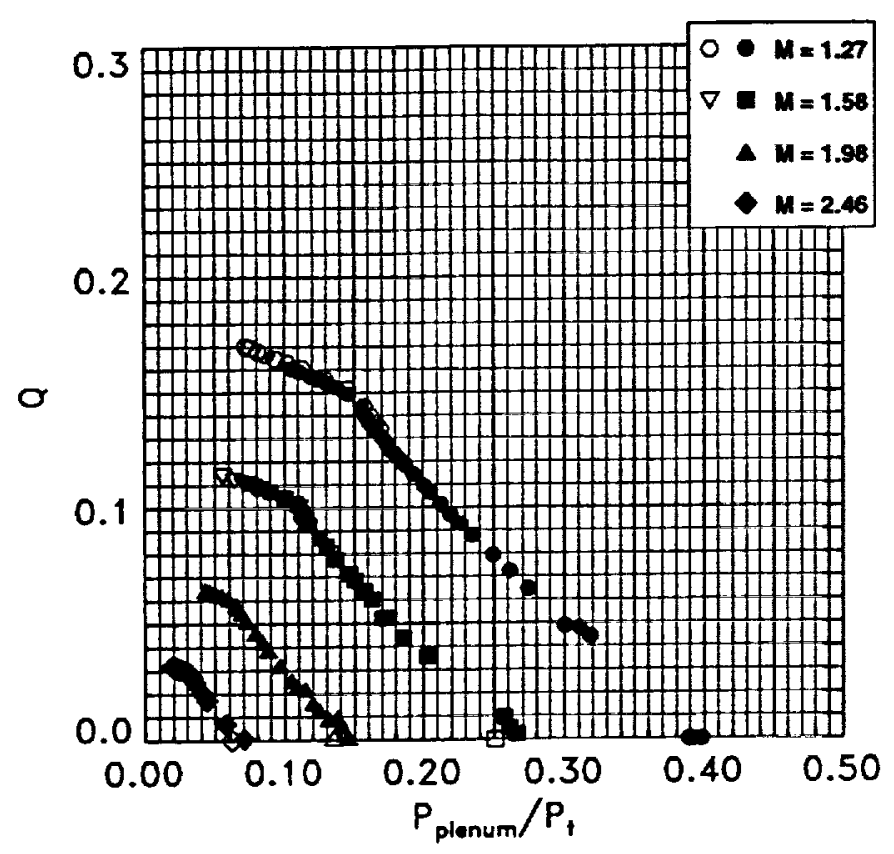

Fig. 8 Sonic flow coefficient distributions: C4

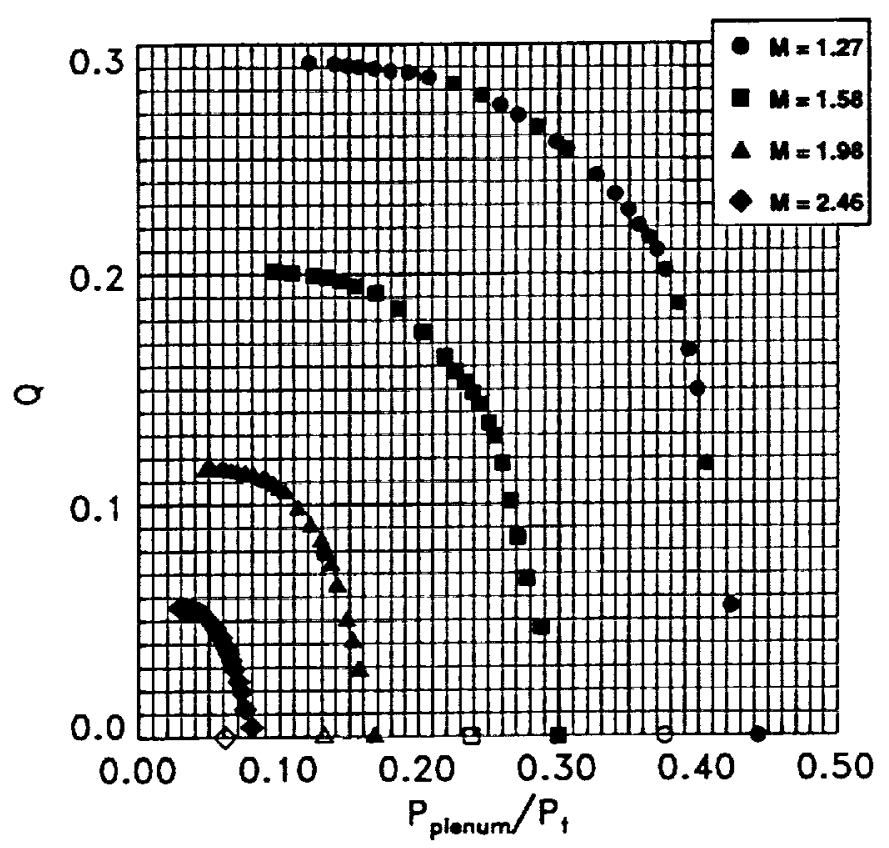

Fig. 10 Sonic flow coefficient distributions: C6 


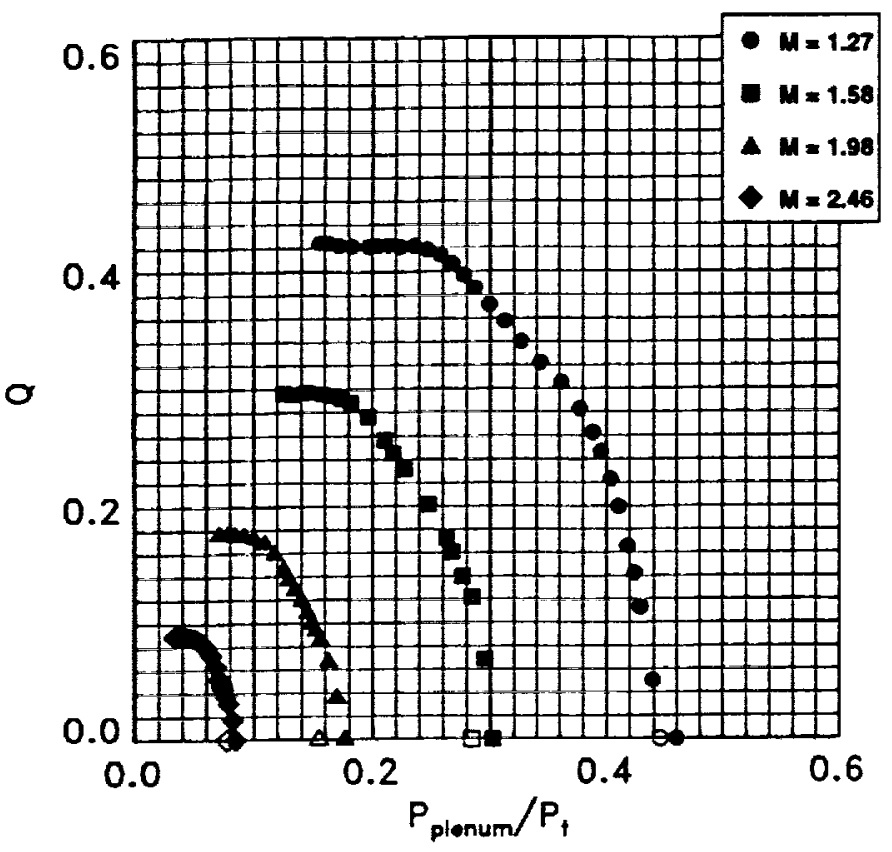

Fig 11 Sonic flow coefficient distributions: C7

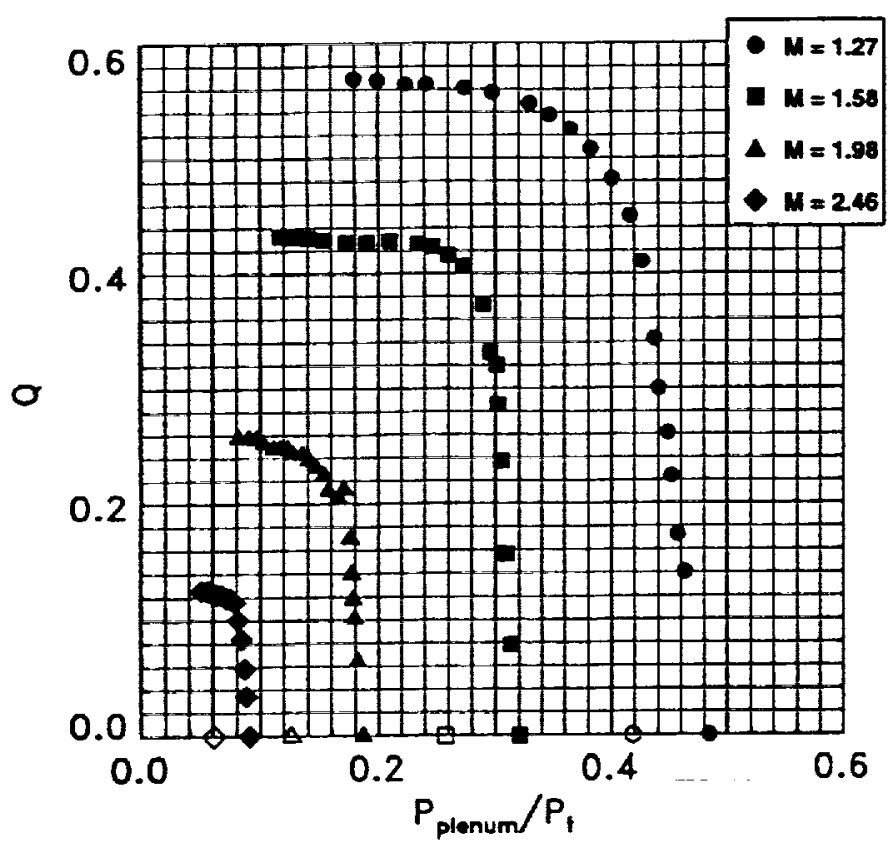

Fig 12 Sonic flow coefficient distributions: $\mathrm{C8}$

General trends will be discussed using Figure 14 as a reference. This figure provides a look at the effect of inclination angle, $\alpha$, on a circular orifice configuration. The $20^{\circ}$ inclined hole configuration, C3, has a maximum sonic flow coefficient approximately three times that of the $90^{\circ}$ inclined hole configuration, $\mathrm{Cl}$. This holds across the entire Mach number range. Configurations with a $20^{\circ}$ inclination angle (C3, C5, C8, C9) display a maximum $Q$ of approximately 0.6 whereas the maximum $Q$ for the analogous $90^{\circ}$ inclination angle configurations (C1, $\mathrm{C} 2, \mathrm{C4}$, ) is approximately 0.2 . The $20^{\circ}$ configurations

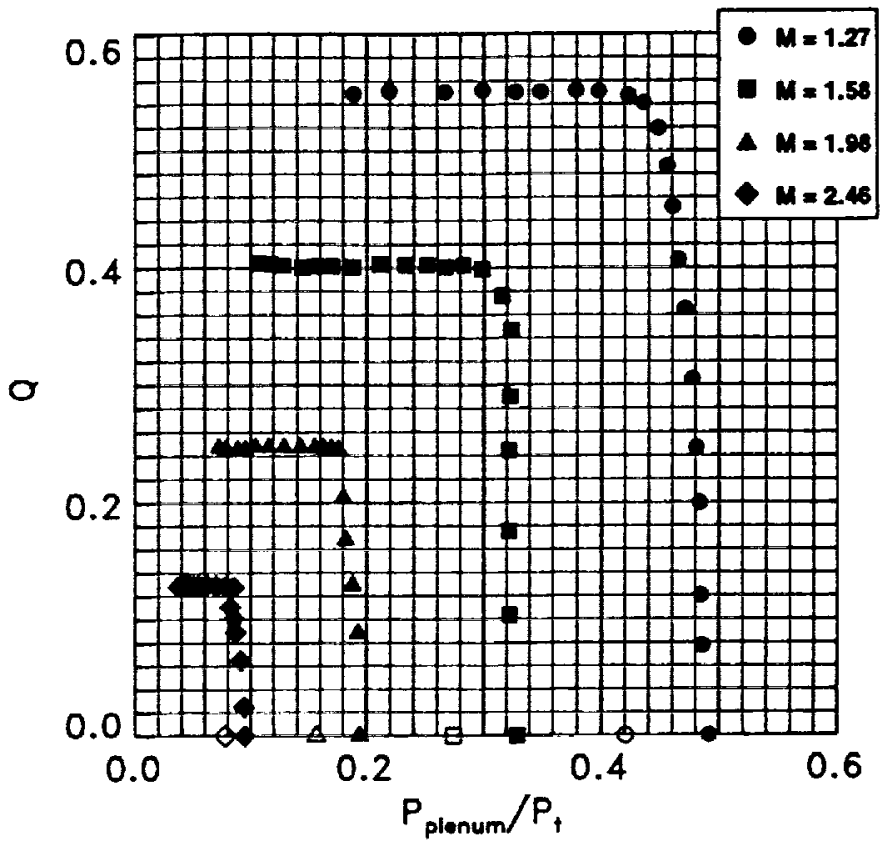

Fig. 13 Sonic flow coefficient distributions: C9

are able to capture a significantly larger fraction of the total pressure associated with the boundary layer than the $90^{\circ}$ configurations due to a ram effect produced by the alignment of the orifice with the boundary layer flow. For any given bleed orifice the flow expands past the leading edge thus providing a measure of flow turning into the orifice. A $90^{\circ}$ configuration immediately separates causing a reduction in the effective area of the bleed passage and suffers even more losses because of the tremendous amount of flow turning required to negotiate the bleed passage. A $20^{\circ}$ configuration presents less separation and more importantly greatly reduces the amount of losses incurred due to flow tuming. It stands to reason that the turming losses experienced by the bleed mass flow vary proportionally with the inclination angle. This effect can been seen in the data of McLafferty and Ranard ${ }^{7}$ where the recovery curve for a $20^{\circ}$ inclined configuration subjected to Mach 0.0 (a true orifice test) exhibits a lower maximum sonic flow coefficient than for approach Mach numbers of 0.5 and 0.7. This trend was also observed by Davis, Hingst, and Bodnar ${ }^{11}$ while investigating single orifice flow coefficient behavior over a Mach number range of 0.0 to 2.0 (nominal).

In general the data in these plots agree with the data of McLafferty and Ranard ${ }^{7}$ even though the multiple hole configurations (with the exception of C9) investigated during this test contain 5 to 6 times as many bleed orifices. From a practical standpoint, $20^{\circ}$ inclined configurations give very little control over the amount of mass flow removed (see solid symbols, Fig 14). During subcritical operation small changes in plenum pressure create large changes in the sonic flow coefficient. Moving to critical or supercritical operation completely reverses the situation and creates an inflexible system. If the removal of varying precise amounts of boundary layer 


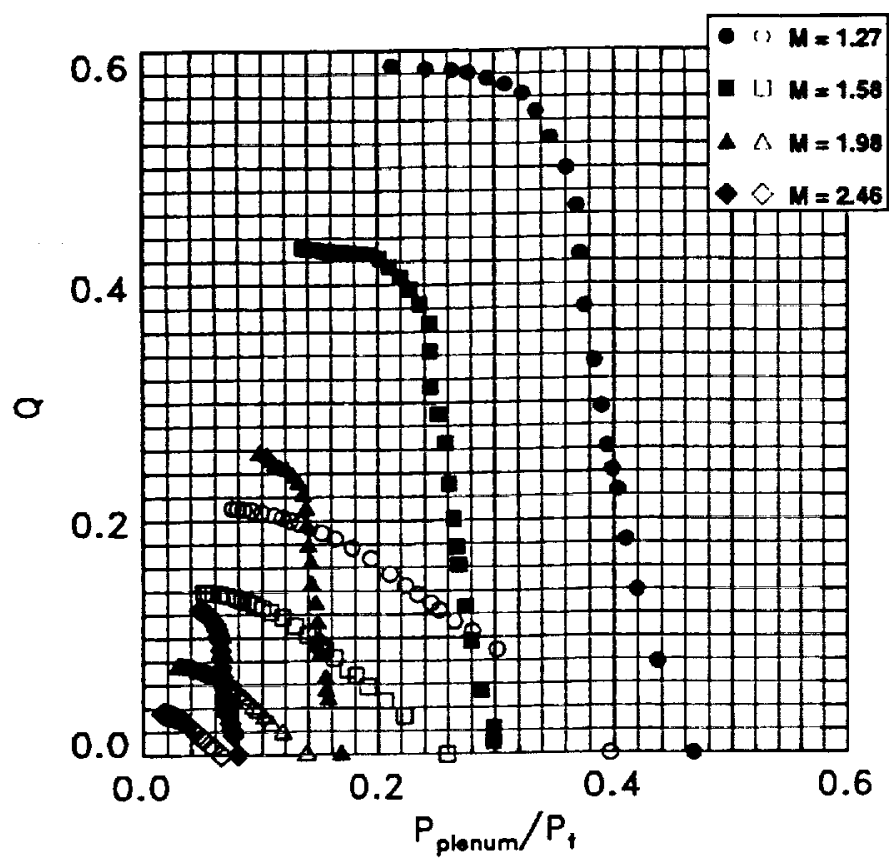

Fig. 14 Sonic flow coefficient distributions:

C3 (solid symbols) vs. C1 (open symbols); affect of inclination angle of the bleed orifice.

mass flow is required, a $90^{\circ}$ inclined configuration provides more resolution when controlling the bleed system via bleed plenum pressure.

The effect of diffusion within the bleed orifice can be seen in Figure 16. Configuration $\mathrm{C} 2$ is identical to $\mathrm{Cl}$ with the exception of an inlet to exit area ratio, $\mathrm{A}^{\prime} / \mathrm{A}$, permutation; $\mathrm{C} 2$ has an area ratio of 1.4. The noticeable difference occurs in the critical/supercritical region of the recovery curve. It is offered that the diffusing geometry requires less turning at the downstream edge of the bole because it is inclined with the flow direction. Consequently the diffusion offers a small increase in pressure recovery for a given amount of bleed mass flow. Since the flow separates off the leading edge of the bleed orifice, the area diffusion in the forward portion of the hole does not provide any improvement in performance. These ideas are illustrated in the Figure 15 below. Overall the performance gains brought about by diffusing a normal hole are very slight.

Figures 18 and 19 begin to illuminate the importance of the streamwise edges of a bleed orifice. Configuration $\mathrm{Cl}$, multiple holes, has better performance than $\mathrm{C} 4$, a single rectangular slot, see Fig.18. The streamwișe edges of $\mathrm{C} 4$ can be boiled down to one circular hole (the semicircular ends of the slot) with a diameter of $1.0 \mathrm{~cm} . \mathrm{Cl}$ is made up of 75 holes with a diameter of $0.635 \mathrm{~cm}$; approximately 47 times the amount of streamwise edges of
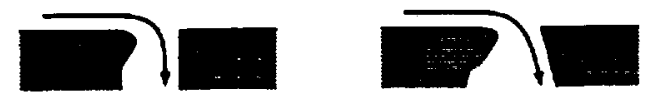

Fig. 15 Ilustration of the effect of area diffusion on bleed flow.

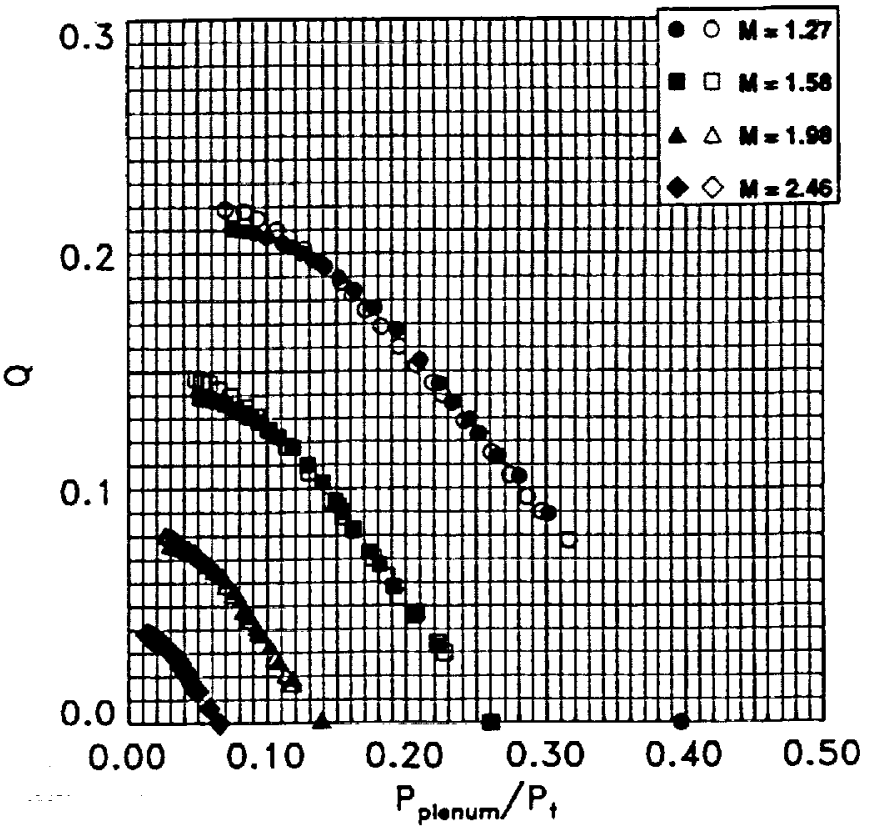

Fig. 16 Sonic flow coefficient distributions:

C1 (solid symbols) vs. C2 (open symbols); affect of diffusing the bleed orifice.

C4. The streamwise edges develop a pressure gradient that promotes flow into the bleed orifice. Figure 17 illustrates a semi-infinte slot compared to three holes. As the flow meets the forward most section of the bole a small expansion occurs at this discontinuity. This expansion creates a lower local static pressure, $P_{0}$, in the immediate vicinity of the hole leading edge while the flow adjacent to the leading edge maintains its original (higher) static pressure, $P$. Consequently a pressure gradient develops across the flow surface which induces flow into
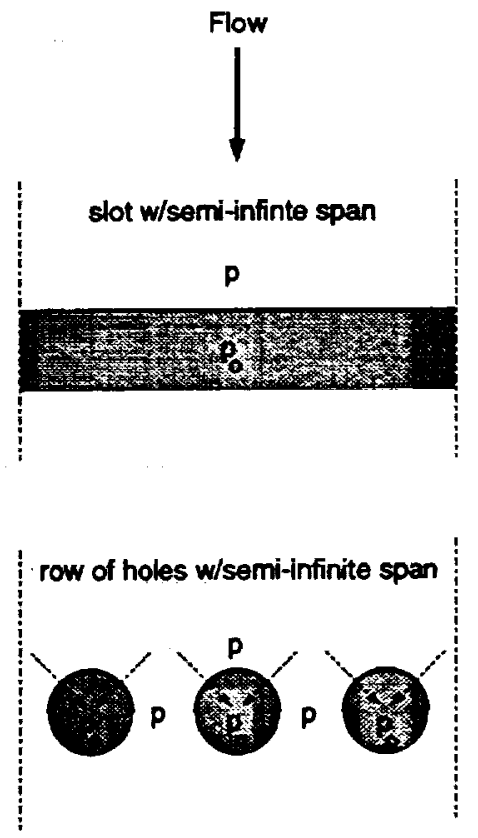

Fig. 17 Relative amount of streamwise edges: a single slot compared to multiple holes. 
the orifice. A large single slot only has this type of activity occurring at its ends. In keeping with this idea, the data show that the streamwise edge effects decrease as the Mach number increases. For Mach 2.46 it becomes nonexistent. As the Mach number increases the rate at which any local activity (such as the flow induced by the pressure gradient) is convected downstream also increases thereby reducing the positive effects of the local activity.

Another issue to keep in mind is the relative magnitude of the pressure forces acting on the bleed orifice over the Mach number range. Separating any analysis of local disturbances such as the aforementioned pressure gradient is not possible when plotting the data in this fashion. It seems unlikely that pressure magnitude alone accounts for the differences in the performance of these configurations at the lower Mach numbers.

Figure 19 provides a comparison of $\mathrm{C} 3$, multiple $20^{\circ}$ inclined holes, with $\mathrm{C5}$, a single $20^{\circ}$ inclined rectangular slot. For this analysis the relative amount of streamwise edges remains the same as for the previous case. Flow induced by the streamwise edges does not appear to have any effect. The relative amount of flow produced by the streamwise edges is small compared to that produced by the ram effect experienced by inclined configurations. The divergence of the recovery curves during critical and supercritical operation for a given Mach number is probably due to each successive row of holes 'seeing' a higher average pressure due to the bleeding activity of its predecessor. A large discrepancy between the $L / d$ values of the two configurations could also account for these differences.

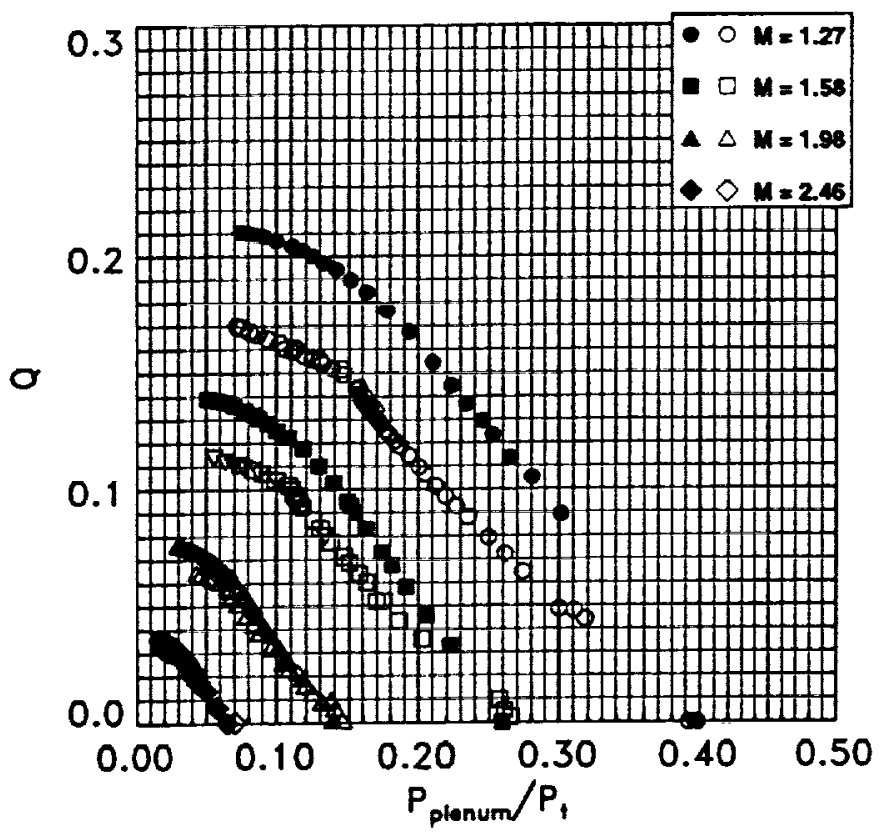

Fig. 18 Sonic flow coefficient distributions: C1 (solid symbols) vs. C4 (open symbols); multiple holes versus a single slot.

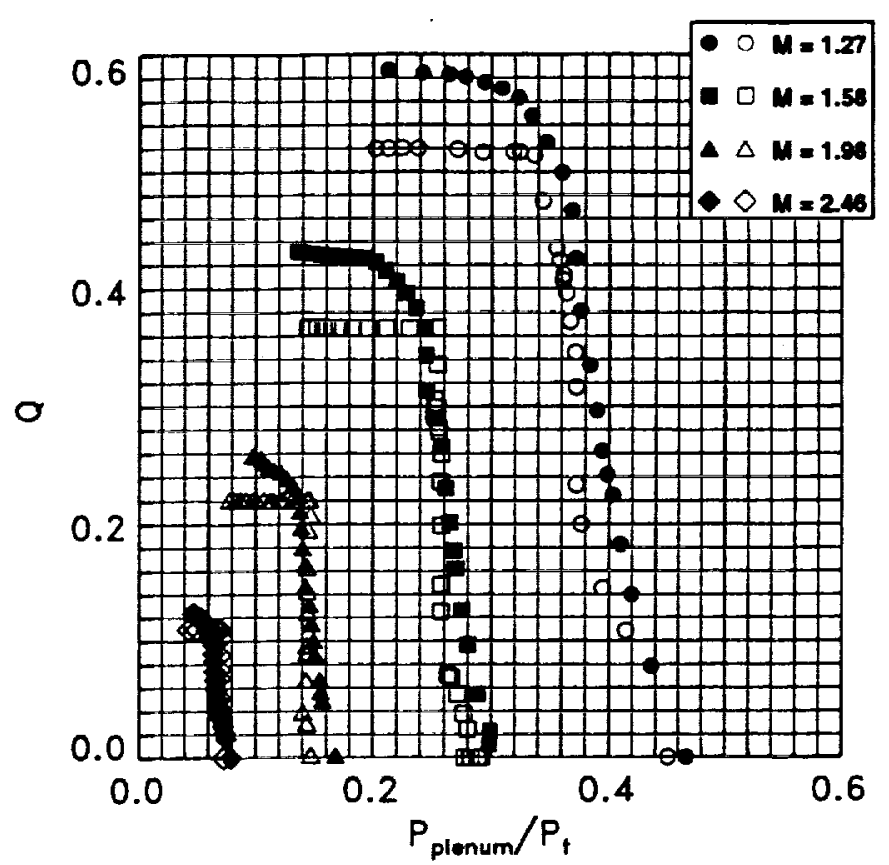

Fig. 19 Sonic flow coefficient distributions: C3 (solid symbols) vs. C5 (open symbols); multiple holes versus a single slot.

Small changes in Reynolds number (brought about by varying the tunnel total pressure) have no effect on the sonic flow coefficient at Mach 1.3. Figure 20 shows recovery curves for three different Reynold's numbers. Some variation is evident but taking into account that $\delta Q / Q \approx 0.0241$ this variation falls within the error band of these curves.

Comparison of a bleed region consisting of multiple orifices to a single similar orifice bas been made utilizing the data of Davis, Hingst, and Bodnar ${ }^{11}$. Figure 21

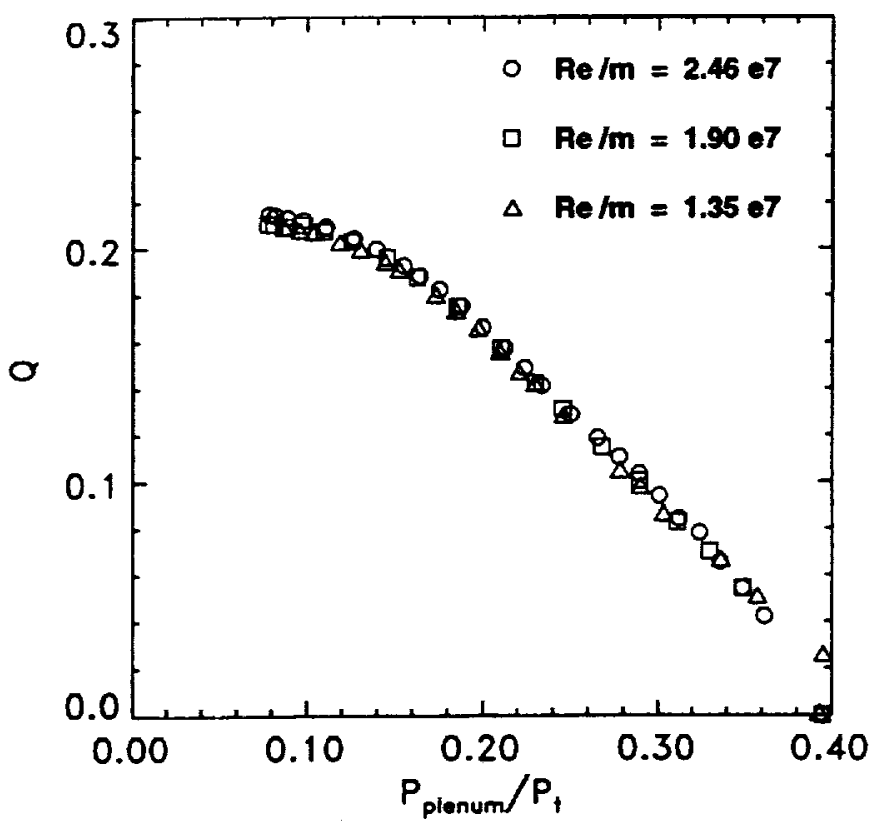

Fig. 20 Sonic flow coefficient distributions: C1; effect of Reynolds Number. 
displays the sonic flow coefficient distributions of configuration $\mathrm{Cl}$ plotted against those of a $90^{\circ}$ single hole with an $\mathrm{L} / \mathrm{d}$ of 2.0. Using the Mach 2.0 data from each configuration shows that the multiple boles have slightly better performance than the single hole as indicated by a different slope in the subcritical portion of the recovery curve and a higher maximum sonic flow coefficient. Given the spacing of the holes in $\mathrm{Cl}$ it would seem that gross mutual interaction effects exist, not that local disturbances from one hole influence another hole but rather each successive row of holes is subjected to a different flow field. With this in mind the increased performance of $\mathrm{Cl}$ could be accounted for by realizing that each successive row of holes pulls off mass flow at an incremental increase in local pressure. Over the combined Mach number range the distributions of both configurations are similar in shape. Despite this slight increase in the relative performance of the two configurations, the maximum values of $Q$ (as a function of Mach number) are monotonically ordered suggesting an order of magnitude similarity their in performance.

Comparison of the $20^{\circ}$ inclined multiple configuration, $\mathrm{C} 3$, with a single $20^{\circ}$ inclined hole strengthens the conjecture on the mutual interaction phenomenon discussed above. Figure 22 displays the sonic flow coefficient distributions of configuration $\mathrm{C} 3$ plotted against those of a $20^{\circ}$ inclined single hole with a $\mathrm{L} / \mathrm{d}$ of $2.0^{11}$. As with the previous analysis the sonic flow coefficient distributions are similar in shape over the Mach number range which implies similar operating characteristics for a single orifice. However, there is a much more dramatic increase in maximum performance of the multiple hole configuration over the single hole configuration at the Mach 2.0 operating condition. This is to be expected as a $20^{\circ}$ inclined orifice operates with a ram effect and each successive row acts upon a significantly different flow field (relative to a $90^{\circ}$ inclined orifice configuration). Note that the maximum $\mathrm{Q}$ for $\mathrm{C} 3$ at Mach 1.58 is approximately equal to the maximum $Q$ for the single hole configuration at Mach 1.44. For this particular comparison the similarity in performance is not as strong as for the $90^{\circ}$ inclined case.

The most significant result of this effort is displayed in Figure 23. This figure highlights the effect of preconditioning the approach flow for $90^{\circ}$ inclined orifices by merging a NACA flush inlet with the upstream edge of the hole. Performance increased by approximately fifty percent across the Mach number range. The performance gained by this preconditioning is due to a combination of flow turning and a pressure gradient acting across the streamwise edges of the flush inlet. The flush inlet increases the amount of streamwise edges that each bleed bole can present to the approach flow, see Fig. 24. In this illustration the streamwise edges are the relatively thicker lines of the hole geometry. Figure 25 displays the effect of preconditioning (identical to the previous case) the approach flow for $20^{\circ}$ inclined orifices. The data

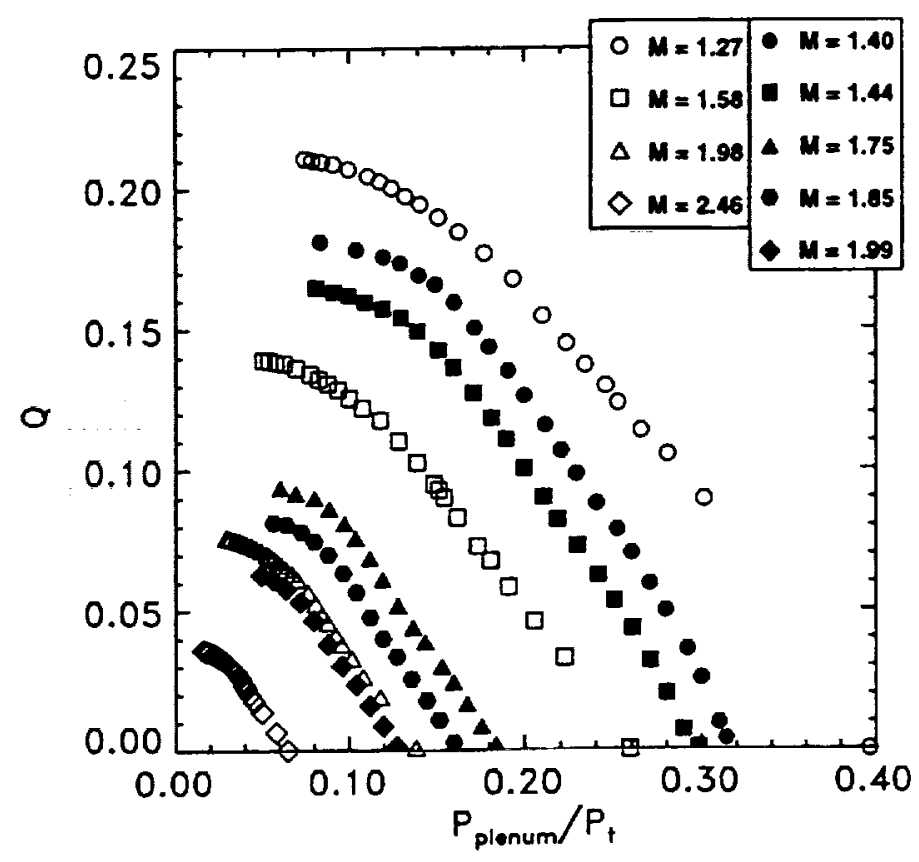

Fig. 21 Sonic fiow coefficient distributions: C1-Multiple holes (open symbols) vs. single hole (solid symbol); gross mutual interaction effects.

here reinforces the idea that the gains in performance are a combination of flow turning and local pressure gradient activity. For the $20^{\circ}$ inclined orifices the maximum performance is not affected. The amount of flow into the orifice attributed to the local activity created by the flush inlet is a relatively small percentage of the total mass flow of a given orifice which is dominated by the ram effect discussed previously. There does appear to be some

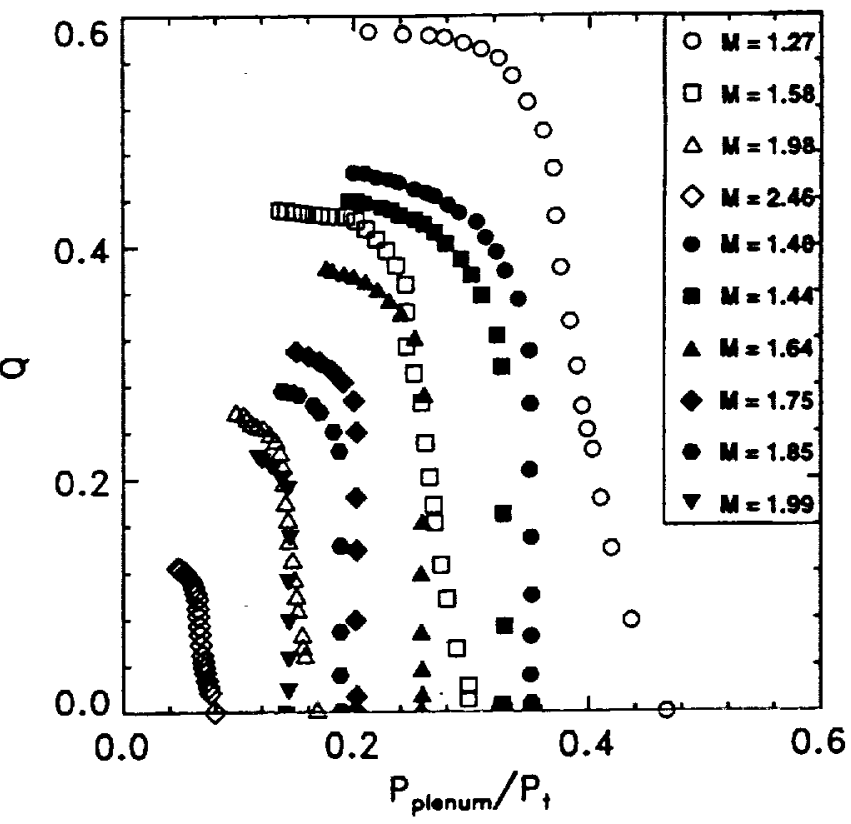

Fig. 22 Sonic flow coefficient distributions: C3-Multiple holes (open symbols) vs. single hole (solid symbol); gross mutual interaction effects. 


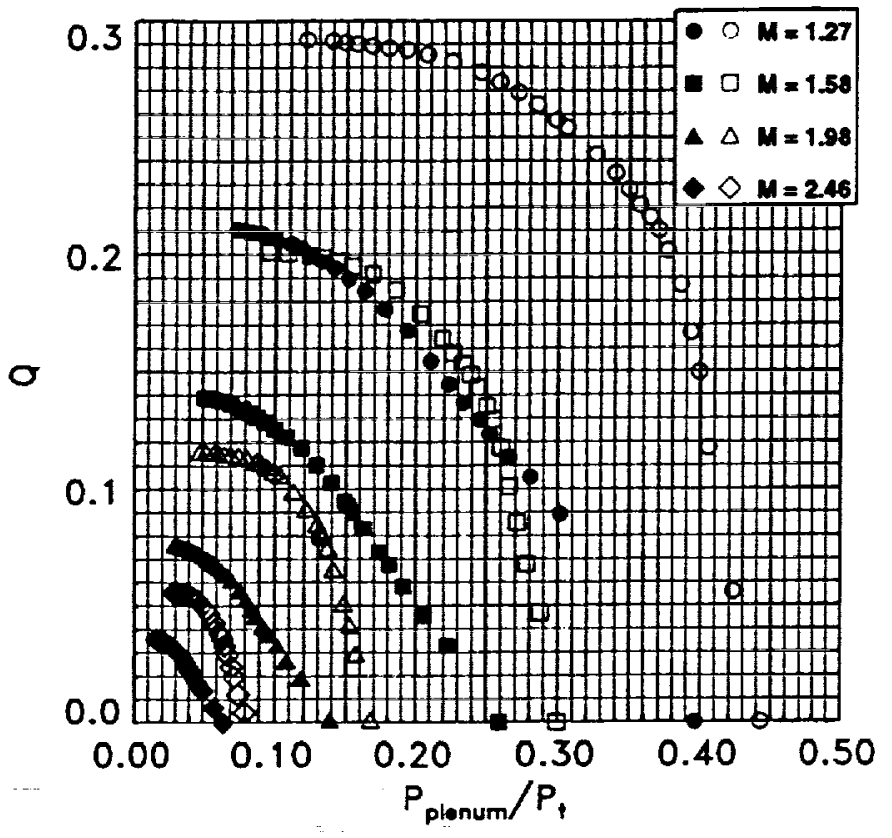

Fig. 23 Sonic flow coefficient distributions: C1 (solid symbols) vs. C6 (open symbols); effect of preconditioning the approach flow for $90^{\circ}$ holes.

gains in the subcritical portion of the recovery curves. At these operating conditions the amount of flow increase attributed to the flush inlet is a contributing percentage of the mass flow through the bleed orifice.

Comparison of a preconditioned $20^{\circ}$ inclined hole with a preconditioned $20^{\circ}$ diffusing channel is shown in figure 26. A decrease in maximum performance occurs at the low Mach numbers. The sensitivity to bleed plenum pressure during subcritical operation is even more pronounced for the diffusing channels than for the holes. Likewise, the insensitivity to plenum pressure during critical/supercritical operation is more pronounced for the

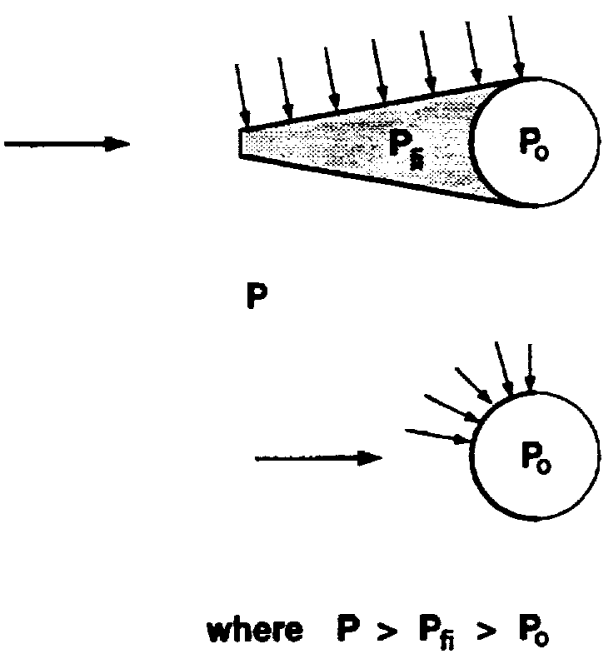

Fig. 24 Relative amount of streamwise edges over which a flow inducing pressure gradient can act: preconditioned $90^{\circ}$ hole versus a standard $90^{\circ}$ hole.

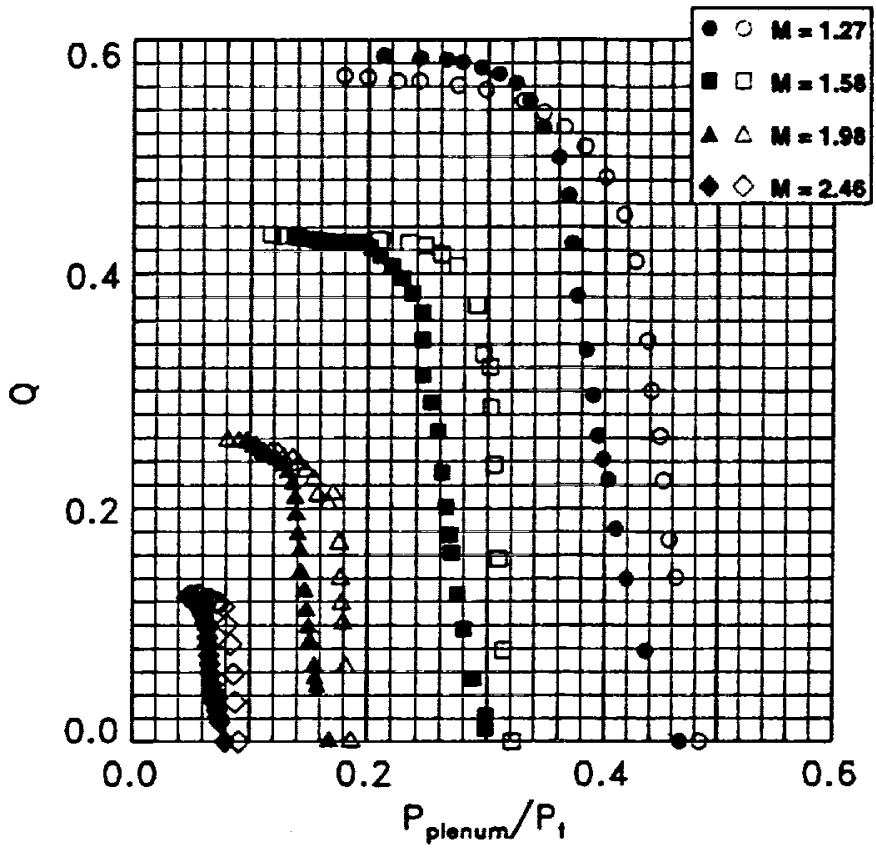

Fig. 25 Sonic flow coefficient distributions: C3 (solid symbols) vs. C8 (open symbols); effect of preconditioning the approach flow for $20^{\circ}$ holes.

diffusing channels. This insensitivity may be a function of the gross mutual interaction occurring between rows of orifices. There are twice as many rows for the preconditioned $20^{\circ}$ inclined hole configuration as there are for the diffusing channel configuration. The same type of dramatic discontinuity in sensitivity to bleed plenum pressure is exhibited by C5, a single $20^{\circ}$ inclined slot.

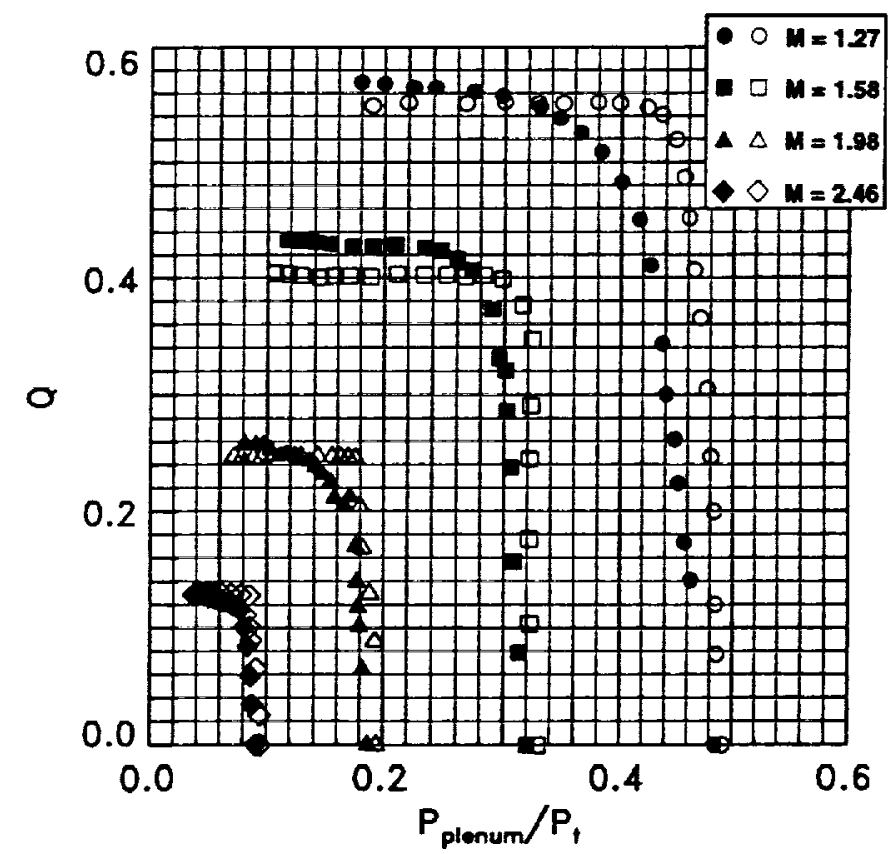

Fig. 26 Sonic flow coefficient distributions: $C 8$ (solid symbols) vs. C9 (open symbols); comparison of a slanted hole versus a slanted diffusing channel. 
To reiterate, this type of plot is developed with an inlet aerodynamicist in mind. If global modeling is the desired goal then the approach by Dittrich and Graves ${ }^{12,13}$ or Rhode ${ }^{14}$ is more appropriate. Their approach involves defining the bleed orifice efficiency in terms of an ideal jet flow then showing it as a function of the suction pressure differential across the orifice. This makes sense because the flow through a bleed orifice is a pressure driven phenomenon. This method begins to collapse the family of curves generated by the method used in this report into a single curve making the data more conducive to modeling.

\section{Concluding Remarks}

The following statements are put forth based on experience gained during this investigation:

1. Extrapolating the performance of a single bleed orifice to the performance of a bleed region consisting of multiple similar orifices provides a general estimate of that performance. The strength of this estimate is inversely proportional to the amount of gross mutual interaction effects occurring within the bleed region.

2. Area diffusion of a $90^{\circ}$ inclined hole does not provide significant improvements in performance. This may not be true for bleed orifices which are more closely aligned with the incoming flow. The higher pressures associated with the ram effect of the aligned geometry may benefit from area diffusion.

3. Small changes in Reynold's number do not affect the performance of $90^{\circ}$ inclined hole with an $\mathrm{L} / \mathrm{d}$ of 1.0 .

4. The increased efficiency of a multiple $90^{\circ}$ inclined hole bleed region relative to a single large slot can be attributed to the increased amount of streamwise edges associated with the holes. Streamwise edges create a local flow field around the orifice which establishes a pressure gradient into the orifice. Slanted holes versus a slanted slot do not exhibit the same dramatic increase in efficiency because the ram effect due to alignment with the approach flow is the primary mechanism driving the bleed mass flow.

5. Merging a NACA flush inlet with a $90^{\circ}$ inclined hole increases the efficiency of the configuration by $50 \%$ across the Mach number range tested. Improvements to a $20^{\circ}$ inclined hole configuration are much more subtle; again owing to the dominance of the ram effect created by this geometry.

It is important to keep in mind that the comparisons made bere involve configurations that at best have a constant inclination angle. Only the comparison of configurations $\mathrm{Cl}$ and $\mathrm{C} 2$ have a constant $\mathrm{L} / \mathrm{d}$ ratio. Current work in this area suggests that the $L / d$ ratio has an effect on the fundamental flow physics of the bleed orifice. As stated earlier this investigation merely 'scratched the surface' of the available permutations and is by no means a definitive study of any particular effect.

\section{References}

[1] Cubbison, R. W., Meleason, E. T., , and Johnson, D. F., "Effect of Porous Bleed in a HighPerformance Axisymmetric, Mixed Compression Inlet at Mach 2.50," NASA Lewis Research Center TM X-1692, 1968.

[2] Sanders, B. W. and Cubbison, R. W., "Effect of Bleed-System Back Pressure and Porous Area on the Performance of an Axisymmetric Mixed Compression Inlet at Mach 2.50," NASA Lewis Research Center TM X-1710, 1968.

[3] Wasserbauer, J. F. and Choby, D. A., "Mach 2.5 Performance of a Bicone Inlet with Internal Focused Compression and 40Research Center TM X-2294, 1971.

[4] Wasserbauer, J. F., Shaw, R. J., and Neumann, H. E., "Minimizing Boundary Layer Bleed for a Mixed Compression Inlet," NASA Lewis Research Center TM X-71461, 1973.

[5] Wasserbauer, J. F., Shaw, R. J., , and Neumann, H. E., "Design of a Very-Low-Bleed Mach 2.5 Mixed Compression Inlet with 45Contraction," NASA Lewis Research Center TM X-3135, 1975.

[6] Shaw, R. J., Wasserbauer, J. F., and Neumann, H. E., "Boundary Layer Bleed System Study for a Full Scale, Mixed Compression Inlet with 45Contraction," NASA Lewis Research Center TM X-3358, Mar. 1976.

[7] McLafferty, G. M. and Ranard, E., "Pressure Losses and Flow Coefficients of Slanted Perforations Discharging from Within a Simulated Supersonic Inlet," United Aircraft Corporation Report R-0920-1, Dec. 1958.

[8] on Fluid Meters, A. R. C., Fluid Meters, Their Theory and Application. Sixthth ed., American Society of Mechanical Engineers, 29 West Thirty-Ninth Street, New York 18, N.Y., 1971.

[9] on Fluid Meters, A. R. C., Measurement of Fluid Flow in Pipes Using Orifice, Nozzle, and Venturi, American Society of Mechanical Engineers, 345 East Forty-Seventh Street, New York, N.Y., 1985.

[10] Frick, C., Davis, W., Randall, , and Mossman, , "An Experimental Investigation of NACA Submerged Duct Entrances," NACA ACR 5120, 1945.

[11] Davis, D. O., Hingst, W. R., and Bodner, J. P., "Flow Coefficient Behavior for Isolated Normal and 20 Degree Boundary-Layer Bleed Holes," NASA Technical Memorandum 106816, 1995. 
[12] Dittrich, R. T. and Graves, C. C., “Discharge Coefficients for Combustor-Liner Air-Entry Holes, PART I - Circular Holes with Parallel Flow," NACA Technical Note 3663, Apr. 1956.

[13] Dittrich, R. T., “Discharge Coefficients for CombustorLiner Air-Entry Holes, PART II - Flush Rectangular
Holes, Step Louvers, and Scoops," NACA Technical Note 3924, Apr. 1958.

[14] Rhode, J. E., Richards, H. T., and Metger, G. W., "Discharge Coefficients for Thick Plate Orifices with Approach Flow Perpendicular and Inclined to the Orifice Axis," NASA Technical Note 3924, Apr. 1966. 
REPORT DOCUMENTATION PAGE

Form Approved

OMB No. 0704-0188

Public reporting burden for this collection of inlomation is estimated to average 1 hour per response, including the tirne for revlewing instructions, searching existing data cources, gathering and maintalning the data needed, and completing and reviewing the collection of intormation. Send comnetorate for Inlormation Operations and Reports. 1215 Jellerson collection of information, including suggestons $2202-4302$, and to the Otfice of Management and Budgex, Paperwork Reduction Project (0704-018B). Washington, DC 20503.

\begin{tabular}{l|l|l|} 
1. AGENCY USE ONLY (Leave blank) & 2. REPOAT DATE & 3. REPOAT TYPE AND DATES COVERED
\end{tabular}

January 1995

Technical Memorandum

\section{TITLE AND SUBTILE}

Flow Coefficient Behavior for Boundary Layer Bleed Holes and Slots

6. AUTHOR(S)

B.P. Willis, D.O. Davis, and W.R. Hingst

\section{PERFORMING ORGANIZATION NAME(S) AND ADDRESS(ES)}

National Aeronautics and Space Administration

Lewis Research Center

Cleveland, Ohio 44135-3191

9. SPONSORINGMONITORING AGENCY NAME(S) AND ADDRESS(ES)

National Aeronautics and Space Administration

Washington, D.C. 20546-0001
5. FUNDING NUMBERS

WU-505-62-52

8. PERFORMING ORGANIZATION REPORT NUMBER

E-9420

10. SPONSORING/MONITORING AGENCY REPORT NUMBER

NASA TM-106846

AIAA-95-0031

11. SUPPLEMENTARY NOTES

Prepared for the 33rd Aerospace Sciences Meeting and Exhibit sponsored by the American Institute of Aeronautics and Astronautics, Reno, Nevada, January 9-12, 1995. Responsible person, B.P. Willis, organization code 2660, (216) 433-2176.

12a. DISTRIBUTIONAVAILABILITY STATEMENT 12b. DISTRIBUTION CODE

Unclassified - Unlimited

Subject Categories 02, 07, and 34

This publication is available from the NASA Center for Aerospace Information, (301) 621-0390.

13. ABSTRACT (Maximum 200 words)

An experimental investigation into the flow coefficient behavior for nine boundary layer bleed orifice configurations is reported. This test was conducted for the purposes of exploring boundary layer control through mass flow removal and does not address issues of stability bleed. Parametric data consist of bleed region flow coefficient as a function of Mach number, bleed plenum pressure, and bleed orifice geometry. Seven multiple hole configurations and two single slot configurations were tested over a supersonic Mach number range of 1.3 to 2.5 [nominal]. Advantages gained by using multiple holes in a bleed region instead of a single spanwise slot are discussed and the issue of modelling an entire array of bleed orifices based on the performance of a single orifice is addressed. Preconditioning the flow approaching a $90^{\circ}$ inclined (normal) hole configuration, resulted in a significant improvement in the performance of the configuration. The same preconditioning caused only subtle changes in performance for $20^{\circ}$ inclined (slanted) configuration.

\section{SUBJECT TERMS}

Flow coefficient behavior; Mass flow removal; Boundary layer control bleed; Bleed orifices; Supersonic

17. SECURITY CLASSIFICATION
OF REPORT
Unclassified
Unclassified

18. SECURTY CLASSIFICATION
OF THIS PAGE
Unclassified

Unclassified
15. NUMBER OF PAGES

16

16. PRICE CODE

A03 